\title{
Serum Beta-2 Microglobulin: a Possible Marker for Disease Progression in Egyptian Patients with Chronic HCV Related Liver Diseases
}

\author{
SM Ouda ${ }^{1}$, AM Khairy ${ }^{2 *}$, Ashraf E Sorour ${ }^{1}$, Mikhail Nasr Mikhail ${ }^{1}$
}

\begin{abstract}
Background: Egypt has the highest prevalence of HCV infection in the world ( 14.7\%). Around 10-15\% of $\mathrm{HCV}$-infected persons will advance to cirrhosis within the first 20 years. The incidence of $\mathrm{HCC}$ is expected to grow in the next two decades, largely due to $\mathrm{HCV}$ related cirrhosis, and detection of $\mathrm{HCC}$ at an early stage is critical for a favorable clinical outcome. No simple reliable non-invasive marker has been available till now. B2M, a non-glycosylated polypeptide composed of 99 amino acids, is one of the components of HLA class I molecules on the surfaces of all nucleated cells. It has been reported that the level of serum B2M is elevated in patients with chronic hepatitis $\mathrm{C}$ and HCV-related HCC when compared to HCV-negative patients or healthy donors. Determining the clinical utility of serum B2M as a marker for disease progression in Egyptian patients with HCV related chronic hepatitis, cirrhosis and hepatocellular carcinoma was the aim of the present study. Materials and Methods: In this analytical cross sectional study 92 participants were included in 4 equal groups: Group (1) non cirrhotic chronic HCV; Group (2) HCV related liver cirrhosis; Group (3) HCC on top of HCV,; and Group (4) healthy controls. History taking, clinical examination, routine labs and abdominal ultrasound were conducted for all patients, PCR and Metavir scores for group (1) patients, and triphasic CT abdomen and AFP for Group (3) patients. B2M levels were measured in serum with a fully-automated IMX system. The mean serum B2M level of Group (1) was 4.25 $\pm 1.48 \mu \mathrm{g} / \mathrm{ml}$., Group (2) was 7.48 \pm 3.04 , Group (3) was 6.62 \pm 2.49 and Group (4) was 1.62 \pm 0.63 . Serum B2M levels were significantly higher in diseased than control group (p<0.01) being significantly higher in cirrhosis $(7.48 \pm 3.04)$ and HCC groups $(6.62 \pm 2.49)$ than the HCV group (4.25 \pm 1.48$)$ $(\mathbf{p}<0.01)$. There was a significant correlation between B2M Level and ALK, total and direct bilirubin and INR $(p<0.05)$, and a significant inverse correlation between B2M level and albumin, total proteins, HB andWBCS values $(\mathbf{p}<0.05)$. There was no significant correlation between B2M level and viral load or Metavir score, largest tumour size or AFP ( $\mathbf{p}>\mathbf{0 . 0 5}$ ). The best B2M cut-off for HCV diagnosis was 2.6 with a sensitivity of $100 \%$, a specificity of $92 \%$, a positive predictive value (PPV) of $97 \%$ and a negative predictive value (NPV) of $100 \%$. The best B2M cut-off for HCC diagnosis was 4.55 which yielded sensitivity, specificity, positive predictive value, negative predictive values of $74 \%, 62 \%, 39.5,87.8 \%$ respectively (p-value $<0.01$ ) while best cut-off for cirrhosis was 4.9, with sensitivity $74 \%$ and specificity $74 \%$.The sensitivity for HCC diagnosis increased upon B2M and AFP combined estimation to $91 \%$, specificity to $79 \%$, NPV to $95 \%$ and accuracy to $83 \%$. Conclusions: Serum B2M level is elevated in HCV related chronic liver diseases and may be used as a marker for HCV disease progression towards cirrhosis and carcinoma.
\end{abstract}

Keywords: Serum- B2M-HCV- HCC- progression- marker

Asian Pac J Cancer Prev, 16 (17), 7825-7829

\section{Introduction}

About130-170 million people are chronically infected with HCV and more than 350,000 people die from HCVrelated liver diseases each year (Chung and Baumert 2014; Cuadros et al., 2014; Feld et al., 2014). The rate of progression to cirrhosis is highly variable, and is influenced by several factors, including age of initial HCV infection, degree of inflammation and fibrosis on liver biopsy, and co-morbid conditions Those with cirrhosis are at increased risk of developing HCC (Kanwal and Bakon , 2012; Hajarizadeh et al., 2013; Flemming et al., 2014).
The problem of the development of biomarkers capable of non-invasive staging of fibrosis in the liver is difficult due to the fact that the process of fibrogenesis is a component of the normal healing response to injury, or invasion by other pathogens (Baranova et al., 2011). Serum AFP levels of more than $200 \mathrm{ng} / \mathrm{ml}$ are considered diagnostic for HCC; however, such high values are observed only in a small percentage of patients. Ultrasound surveillance even performed at three months interval could not improve detection of small HCC because of limitations in recall procedures (Behne and Sitki, 2012; Mourad et al., 2013). 
B2 microglobulin (B2M) is an amino acid peptide, a component of MHC class I molecules, which are present on all nucleated cells that present self and non self antigens to cell surfaces. A high serum level of B2M was detected in many infectious diseases including HCV (Riolobos et al., 2013; Changhoon et al., 2015). Serum B2M was elevated in $\mathrm{HCV}$ patients and HCV-related HCC when compared to HCV-negative patients or healthy donors (Saito et al., 2010; Saleh, 2012; Huckans et al., 2014). Yet, other studies claim no true relation between serum B2M and disease progression (Tabayoyong and Zavazava , 2007 ).

\section{Materials and Methods}

\section{Clinical samples}

A total of 92 blood samples (Group (1): 23 chronic $\mathrm{HCV}$; Group (2): 23 cirrhotics on top of HCV, Group (3): $23 \mathrm{HCC}$ on top of HCV, andGroup (4): 23 healthy controls) were withdrawn after informed consent from patients and volunteer visitors at the Department of Endemic Medicine, KasrAlainy Hospital (Cairo, Egypt) from April till October 2013. Laboratory tests were done in the Clinical pathology and Medical Microbiology and Immunology departments, Kasr Alainy, Cairo University.

All patients and healthy controls were HBsAg -ve, with normal urea and creatinine level, no history of autoimmune diseases or malignancies other than HCC. Patients with liver disease other than HCV such as acute hepatitis, metabolic hepatitis, and history of alcohol consumption or hepatotoxic drug use were excluded.

All subjects were subjected to full medical history taking, clinical examination, routine Laboratory investigations (CBC, Liver function tests, Kidney function tests, coagulation profile) and abdominal Ultrasound examination. HCV Quantitative PCR and Metavir score of fibrosis were obtained from Group (1) patients, Triphasic
CT abdomen and AFP were required to confirm HCC diagnosis in Group (3).

\section{Specimen collection, Preparation, and Storage}

A volume of $10 \mathrm{ml}$ of blood was withdrawn from each participant under complete aseptic conditions, divided equally into 2 volumes for the sake of routine laboratory investigations and serum separation by centrifugation. Each separated serum sample was divided into 4 aliquots to prevent repeated freezing and thawing of the same aliquot which may alter the results. Only clear, non haemolyzed serum samples were used. Sera were stored at $-20^{\circ} \mathrm{C}$ till processing. Sera were brought to room temperature prior to testing. Frozen samples were completely thawed and mixed well prior to testing.

\section{ELISA Testings}

All serum samples were subjected to HBsAg detection using a commercial third generation enzyme immunoassay (Murex HBsAg Version 3, S. Africa), and HCV Ab detection using a commercial third generation enzyme immunoassay (Murex anti-HCV, version 4.0, S. Africa), based on enzyme immune assay (sandwich technique). The tests were done according to manufacturers' instructions.

\section{B2M Detection in serum}

B2M was estimated by the IMX B2-MG assay using fully-automated IMX system (Abbott Laboratory, USA), based on the microparticle immunoassay (MEIA).

\section{Statistical methods}

Quantitative variables presented by number and percent. They were compared by chi-square or Fisher's exact test. These were presented by mean and standard deviation (SD) if normally distributed and by median and inter quartile range (IQR) if not normally distributed.

Table 1. Demographic Data and Investigations for Studied Groups

\begin{tabular}{|c|c|c|c|c|c|}
\hline Mean \pm SD & $\mathrm{HCV}$ & Cirrhosis & $\mathrm{HCC}$ & Controls & $\mathrm{P}$ value \\
\hline Age & $42.2 \pm 8 a$ & $54.8 \pm 7 \mathrm{~b}$ & $58.6 \pm 8 b$ & $32.8 \pm 8 c$ & $<0.01$ \\
\hline Sex(females) & $9(39.1 \%)$ & $9(39.1 \%)$ & $7(30.4 \%)$ & $10(43.5 \%)$ & $>0.05$ \\
\hline $\mathrm{Hb}(\mathrm{g} / \mathrm{L})$ & $13.7 \pm 1.7 \mathrm{a}$ & $10.7 \pm 2.2 b$ & $11.2 \pm 2.3 b$ & $13.4 \pm 1.8 \mathrm{a}$ & $<0.01$ \\
\hline RBCs $(103 / 1)$ & $4.7 \pm 0.9 a$ & $3.8 \pm 1.3 b$ & $3.7 \pm 0.95 b$ & $4.8 \pm 0.64 a$ & $<0.01$ \\
\hline WBCs $(103 / 1)$ & $6.4 \pm 1.9 c$ & $5.8 \pm 3.8 \mathrm{c}$ & $5.5 \pm 2.1 b$ & $7.2 \pm 2 \mathrm{c}$ & $>0.05$ \\
\hline Platelets $(103 / 1)$ & $211 \pm 80 a$ & $113 \pm 94 b$ & $131 \pm 62 b$ & $267 \pm 82 c$ & $<0.01$ \\
\hline $\operatorname{AST}(15-37)$ & $49 \pm 38 a$ & $58 \pm 35 a$ & $79 \pm 40 b$ & $24 \pm 8 c$ & $<0.01$ \\
\hline ALT(30-65) & $56 \pm 44 a$ & $40 \pm 21 \mathrm{a}$ & $51 \pm 28 a$ & $17 \pm 6 b$ & $>0.01$ \\
\hline ALK & $143 \pm 81 a$ & $125 \pm 57 \mathrm{a}$ & $247 \pm 134 b$ & $75 \pm 20 c$ & $<0.01$ \\
\hline T.Bil(mg/dl) & $0.9 \pm .3 \mathrm{a}$ & $4.9 \pm 4.8 \mathrm{~b}$ & $2.8 \pm 3 c$ & $0.4 \pm .2 \mathrm{a}$ & $<0.01$ \\
\hline D.Bil (mg/dl) & $0.23 \pm .11 \mathrm{a}$ & $2.5 \pm 2.6 b$ & $1.4 \pm 1.9 \mathrm{c}$ & $0.08 \pm .05 \mathrm{a}$ & $<0.01$ \\
\hline $\operatorname{Albumin}(\mathrm{g} / \mathrm{l})$ & $4.3 \pm .47 \mathrm{a}$ & $2.7 \pm .53 \mathrm{~b}$ & $3 \pm .8 \mathrm{~b}$ & $4.2 \pm .7 \mathrm{a}$ & $<0.01$ \\
\hline T.Proteins & $7.5 \pm 0.8 \mathrm{a}$ & $6.5 \pm 0.9 b$ & $6.7 \pm 1.1 b$ & $7.8 \pm 0.6 \mathrm{a}$ & $<0.01$ \\
\hline INR & $1.2 \pm .3 \mathrm{c}$ & $1.5 \pm .4 \mathrm{~b}$ & $1.3 \pm .3 \mathrm{c}$ & $1.1 \pm .08 \mathrm{~d}$ & $<0.01$ \\
\hline Metavir A1/A2 & 15,8 & - & - & - & NA \\
\hline Met. F1-2/ F3 & 14,9 & - & - & - & NA \\
\hline MELD $<20 / \geq 20$ & - & 14,9 & - & - & NA \\
\hline $\mathrm{AFP}(\mathrm{ng} / \mathrm{L})$ & $8 . \pm 3.21$ & $5.6 \pm 1.6$ & $1409.4 \pm 4174.8$ & - & $>0.05$ \\
\hline HFL (n) S/M & - & - & 9,14 & - & NA \\
\hline $\mathrm{B} 2 \mathrm{M}(\mu \mathrm{g} / \mathrm{ml})$ & $4.25 \pm 1.48 \mathrm{a}$ & $7.48 \pm 3.04 b$ & $6.62 \pm 2.49 \mathrm{~b}$ & $1.62 \pm .63 \mathrm{c}$ & $<0.01$ \\
\hline
\end{tabular}

AST: Aspartate Transaminase; ALT: Alanine Transaminase; ALK: Alkaline Phosphatase; T. \&D. Bil: Total\& Direct Bilirubin; INR: International Normalization Ratio; S/M:Single/Multiple; All values are expressed in Mean \pm SD; Different letters mean significant difference at the level of 0.05 or 0.01 
Serum Beta-2 Microglobulin: a Marker for Disease Progression in Egyptian Patients with Chronic HCV Related Liver Disease

Multiple groups were compared by ANOVA or Kruskill

Wallis test respectively. Pearson or Spearman Correlations were used to correlate two continuous variables. Receiver operator characteristic (ROC) curve was constructed to assess B2 micro globulin in discriminating 2 groups. In all tests, $\mathrm{p}$ value was considered significant if less than 0.05 .

\section{Results}

Demographic data and investigations for studied groups are shown in Table (1)

Serum B2M levels were significantly higher in diseased groups than in control group $(\mathrm{p}<0.01)$, and significantly higher in Cirrhosis (7.48 \pm 3.04$)$ and HCC groups $(6.62 \pm 2.49)$ than HCV group $(4.25 \pm 1.48)(\mathrm{p}<0.01)$ (Figure 1).

There was a significant correlation between B2M level and age $(\mathrm{p}<0.01)$. There was a significant inverse correlation between B2M level and $\mathrm{Hb}$ level, Platelet Count, serum albumin and total protein among the studied

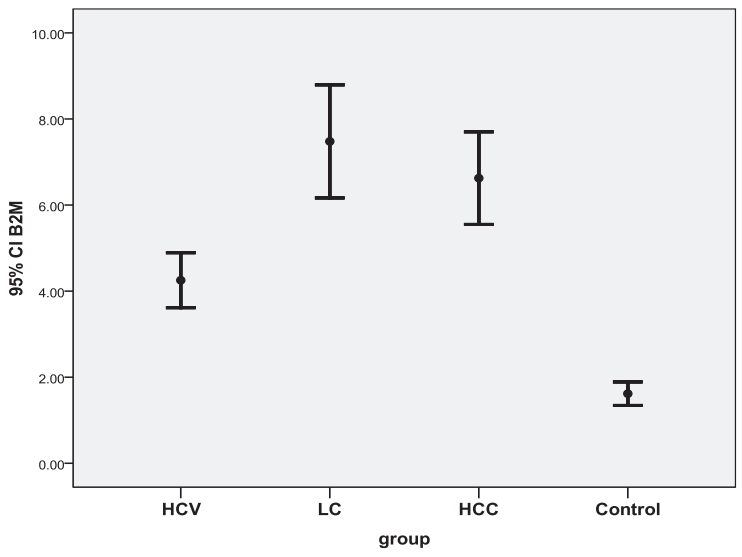

Figure 1. Serum B2M Levels of Studied Groups. Serum B2M levels were significantly higher in diseased than control group $(\mathrm{p}<0.01)$ being significantly higher in Cirrhosis $(7.48 \pm 3.04)$ and HCC groups $(6.62 \pm 2.49)$ than HCV group $(4.25 \pm 1.48)(\mathrm{p}<0.01)$

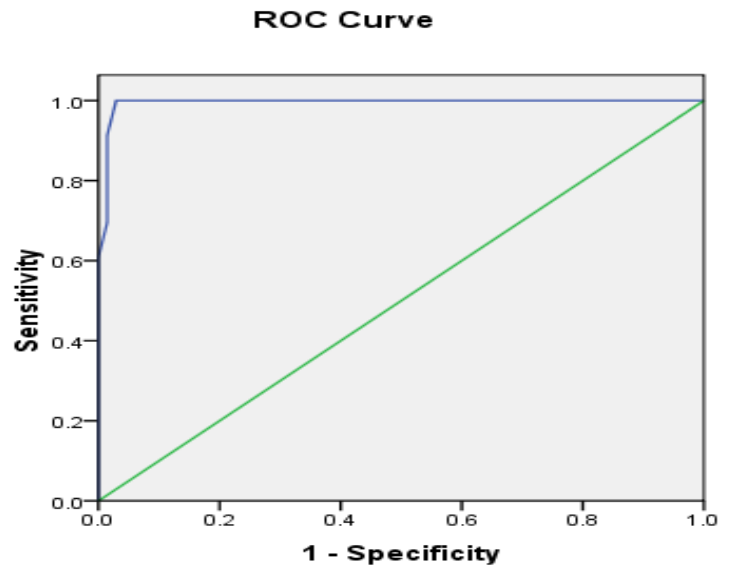

Diagonal segments are produced by ties.

Figure 2. Diagnostic Performance of B2M for Chronic HCV Patients. The best B2M cut-off for HCV diagnosis was 2.6 with sensitivity of $100 \%$, specificity $92 \%$, positive predictive value (PPV) 97\% and negative predictive value( NPV) 100\%
ROC Curve

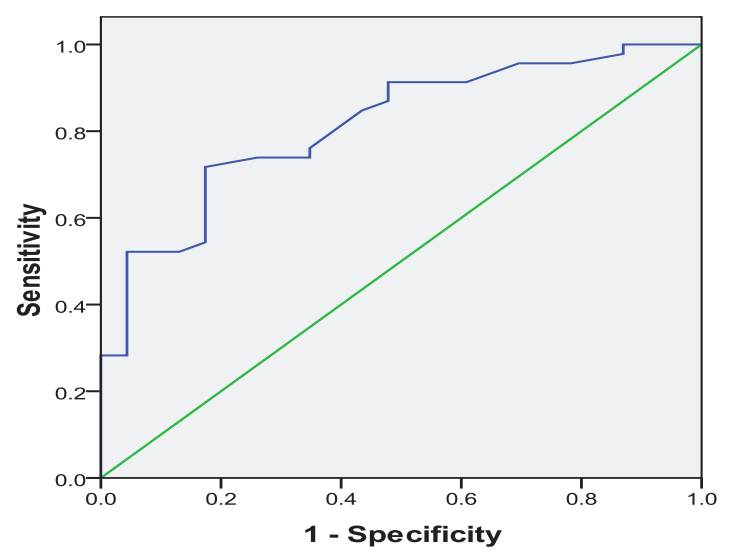

Figure 3. Diagnostic Performance of B2M for Liver Cirrhosis. AUC 0.81 (95\% CI 0.71-0.92), $\mathrm{P}<0.01$, best cut-off 4.9 , at which sensitivity 0.74 and specificity 0.74

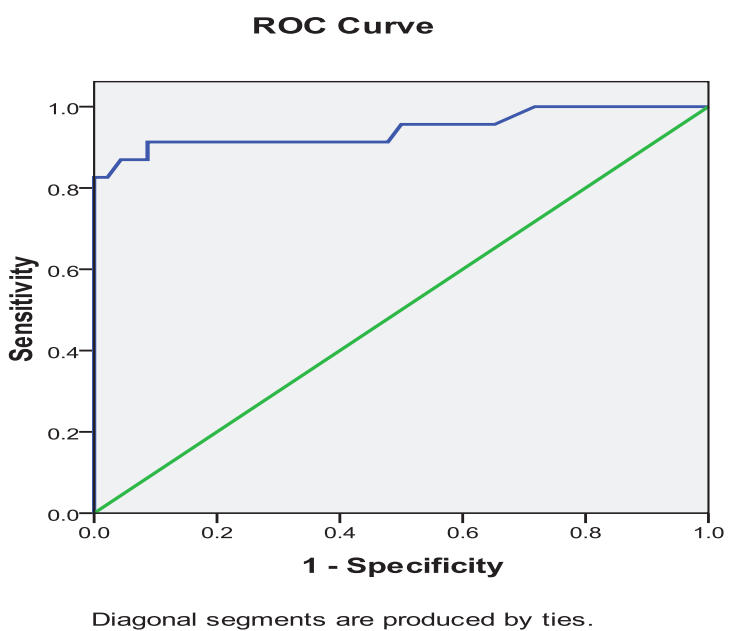

Figure 4. Diagnostic performance of B2M for HCC. The best B2M cut-off for HCC diagnosis was 4.55 which yielded sensitivity, specificity, positive predictive value, negative predictive values of $74 \%, 62 \%, 39.5$, $87.8 \%$ respectively (p value $<0.01$ )

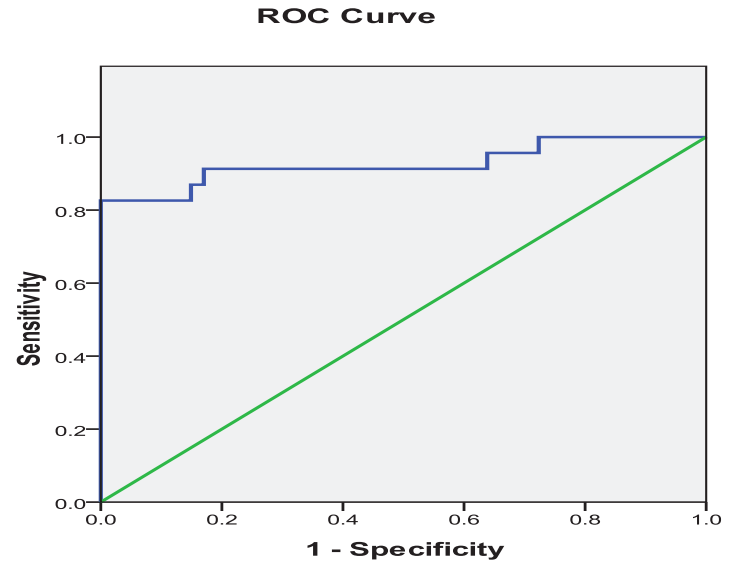

Figure 5. Diagnostic Performance of Combined B2M and AFP for HCC. The sensitivity for HCC diagnosis increased upon B2M \& AFP combined estimation to $91 \%$, specificity to $79 \%$, NPV to $95 \%$ and accuracy to $83 \%$ 


\section{SM Ouda et al}

groups $(\mathrm{p}<0.01)$. There was a significant correlation between B2M level and INR level $(\mathrm{p}<0.01)$, ALK $(\mathrm{p}<0.05)$, total and direct bilirubin levels $(\mathrm{p}<0.01$ and $\mathrm{p}<0.05$ respectively). There was no significant correlation between B2M level and viral load or Metavir score in HCV group ( $>>0.05)$. No significant correlation between B2M level and tumor size or AFP in HCC Group ( $p>0.05)$ was noted.

\section{Performance characteristics of B2M in studied patients}

By categorizing patients into normal and diseased Performance Characteristics of B2M in diagnosis of the HCV related diseases was plotted (Figure 2). At cut-off value of 2.6, the AUC was 0.99 with sensitivity of $100 \%$, specificity $92 \%$, positive predictive value (PPV) $97 \%$ and negative predictive value (NPV) $100 \%$.

By categorizing patients into cirrhotics and non cirrhotics, Performance Characteristics of B2M in diagnosis of the HCV related cirrhosis was plotted (Figure 3 ). At cut-off value of 4.9 ; the AUC was 0.81 with sensitivity of $74 \%$, specificity $74 \%$.

By categorizing the patients $\mathrm{HCC} v s$ non HCC Figure (4), ROC analysis of serum B2M was performed to determine its diagnostic accuracy for HCC.AUC was 0.74 ,the best cutoff was 4.55 which yielded sensitivity, specificity, positive predictive value, negative predictive values of $74 \%, 62 \%, 39.5,87.8 \%$ respectively ( $\mathrm{p}$ value $<0.01)$.

\section{Value of combined B2M and AFP in HCC diagnosis}

The AUC increased significantly to 0.93 upon combined B2M / AFP estimation $(\mathrm{P}<0.01)$ for $\mathrm{HCC}$ diagnosis (Figure 5). The sensitivity, specificity, negative predictive value and accuracy of this combination were $91 \%, 79 \%, 95 \%$ and $83 \%$ respectively.

\section{Discussion}

Serum markers have been proposed as a simple and convenient means to estimate chronic liver disease progression.Although some markers may be effective, the clinical utility of these markers is still limited (Behne and Sitki,2012) .Detecting simple, non invasive, accurate and reliable marker that is linked to clinically important milestones in liver disease progression, such as cirrhosis and HCC, is currently an area of active investigation (Chatterjeea and Mitra 2015).

In the current study, the aim was to assess the possible role of serum B2M level as a marker of disease progression in Egyptian patients with chronic HCV related liver disease.

Serum B2M levels were significantly higher in patients than control group $(\mathrm{p}<0.001)$. This finding goes with Huckans et al. (2014) who conducted a study on altered expression of peripheral immune factors associated with neuro-psychiatric symptom severity in adults with and without chronic hepatitis $C$ virus infection, and found that $\mathrm{B} 2 \mathrm{M}$ levels were higher in in adults with hepatitis $\mathrm{C}$ virus $(\mathrm{n}=39)$ than those without $(\mathrm{n}=40)(\mathrm{p}<0.001)$. This might be attributed to the increased endogenous production of interferons and/or other cytokines associated with viral infection. High serum B2M level is associated with an activated immune response and release by activated lymphocyte (T4/T8 cells), so increase in its level might indicate increasing $\mathrm{HCV}$ replication- related cell death. In HCV chronicity, many differentially expressed genes involved in the pathways of immune system, fibrosis, proliferation, cell growth, and apoptosis have been found to be up- regulated, including major histo-compatibility, and B2M genes (Kim and Wang, 2003; Elgendy et al., 2005; Khaled et al., 2012; Saleh, 2012).

Serum B2M levels were significantly higher in HCC group (6.62 \pm 2.49$)$ than chronic HCV group (4.25 \pm 1.48$)$ $(\mathrm{p}<0.01)$. Other studies reported high serum B2M in HCC patients on top of chronic HCV and suggested that the $\mathrm{B} 2 \mathrm{M}$ in plasma could be used as an early marker to detect imaging-invisible HCC (Maliguarnera et al., 2000; Migliaresia et al., 2000; Saito et al., 2010). In histologically normal liver, HLA class 1 antigens were mainly expressed on liver sinusoidal lining cells rather than on hepatocytes (Asanza et al., 1997). The reason why the phenomenon that histologically normal hepatocytes have no or only weak HLA class 1 antigens expression though liver cancer cells strongly express HLA class antigens, may be related to the unique lymphocytes distribution in liver and NK-cell escape. About $31 \%$ of the liver resident lymphocytes are NK cells. Therefore, re-expression or enhanced expression of HLA class1 antigens on HCC cells would be helpful for inhibiting the non-specific cytotoxicity of NK cells through their inhibitory KIR receptors (Huang, 2002).

In the current study there was a significant correlation between B2M level and age $(\mathrm{p}<0.01)$. This goes with Hamidreza et al. (2013) who reported that serum B2M values are dependent on age in patients with chronic active hepatitis which may be due to dysfunction of the liver.

A significant correlation was found between B2M level and some biochemical parameters (ALK, bilirubin and INR) in the study groups $(\mathrm{p}<0.05)$. A significant inverse correlation was found between B2M level and serum Albumin ,Total proteins, Hb level, WBCs count, and Platelet count in the study groups $(\mathrm{p}<0.05)$. However, No significant correlation was found between B2M and viral load among group 1 patients $(\mathrm{p}>0.05)$. This goes with Asanza et al. (1997) who performed a study on 32 cases to assess the immune-histochemical evidence of immune-pathogenetic mechanisms in chronic hepatitis $\mathrm{C}$ recurrence after of liver transplantation, and reported that in severe hepatic inflammation, high numbers of activated cytotoxic $\mathrm{T}$ cells were found along with marked hepatocellular expression of B2M. Yet, the level of viremia did not correlate with the degree of liver damage.

In this study, no significant correlation was found between B2M and the Metavir score in group1 patients ( $p>0.05$ ). This doesn't go with Quiroga et al. (1994) who found significant correlations between beta 2-microglobulin concentration and Knodell's index $(\mathrm{r}=0.638, \mathrm{P}=0.00045)$, the score of piecemeal necrosis $(\mathrm{r}=0.572, \mathrm{P}=0.0023)$, and the degree of fibrosis $(\mathrm{r}=0.527$, $\mathrm{P}=0.0056)$ in their HCV patients than healthy group. This difference in the results may be due to genotypic variation among study subjects that has an influence on HCV core Ag level as reported by Agha et al. (2004) where they 
Serum Beta-2 Microglobulin: a Marker for Disease Progression in Egyptian Patients with Chronic HCV Related Liver Disease

found the mean $\mathrm{HCV} \mathrm{CAg}$ level was significantly higher with genotypes 1, 2, and 3 and lower with genotype 4, with altered immune reactivity that plays a role in the pathogenesis of chronic hepatitis $\mathrm{C}$.

No significant correlation was found between B2M and tumor size or serum AFP level $(\mathrm{p}>0.05)$ in group 3 patients. This doesn't go with Malaguarnera et al. (2000), who found significant correlation between B2M and tumor size $(\mathrm{r}=+0.3 ; \mathrm{P}=0.02)$, and alpha-fetoprotein $(\mathrm{r}=+0.4 ; \mathrm{P}=0.005)$ in their HCC patients. Upon which they concluded that serum levels of $\mathrm{B} 2 \mathrm{M}$ reflect tumor size. This discrepancy might be due to small sample size in our study. Larger scale studies may be needed to verify the correlation.

Combined AFPand B2M estimation improved AUC for $\mathrm{HCC}$ diagnosis from 0.74 to 0.93 .This goes with Ward et al. (2006) where B2M was the most significantly HCC associated proteomic finding in their study. They mentioned that $\mathrm{B} 2 \mathrm{M}$ might add power to a multi-marker HCC diagnostic panel and concluded that combined estimation of AFP and B2M might add a significant yield rather than $\mathrm{B} 2 \mathrm{M}$ values alone for diagnosis of $\mathrm{HCC}$.

Thus, this hypothesis needs to be explored further by the close monitoring of patients cohorts with $\mathrm{HCV}$ chronic active hepatitis and cirrhosis who are at high risk of HCC and repeated B2M serum profiling in order to reach more confirmatory results.

\section{References}

Agha S, Tanaka Y, Saudy N, et al (2004). Reliability of hepatitis $\mathrm{C}$ virus core antigen assay for detection of viremia in HCV genotypes 1, 2, 3, and 4 infected blood donors: a collaborative study between Japan, Egypt, and Uzbekistan. J Med Virol, 73, 216-22.

Ancha Baranova, Priyanka Lal, Aybike Birerdinc, Zobair M Younossi (2011). Non-Invasive markers for hepatic fibrosis. Gastroenterol, 11, 91 .

Asanza Cilia G, Carmelo Garcia A-Monezo, Gerardo Clement, et al (1997). Immunohistochemical evidence of immunopathogenetic mechanisms in Chronic Hepatitis C Recurrence After Liver Transplantation. Hepatol, 26, 755-63.

Behne Tara and Sitki M. Copur (2012). Biomarkers for Hepatocellular Carcinoma. Int J Hepatol, 859076.

Changhoon Yoo, Dok Hyun Yoon, Shinkyo Yoon, et al (2015). Prognostic impact of $\beta 2$-microglobulin in patients with non-gastric mucosa-associated lymphoid tissue lymphoma. Leukaemia Lymphoma, 56, 688-93.

Chatterjeea Reshmi and Mitra Abhisek (2015). An overview of effective therapies and recent advances in biomarkers for chronic liver diseases and associated liver cancer. Int Immunopharmacol, 24, 335-45.

Chung Raymond T., and Baumert F (2014). Curing chronic hepatitis c. the arc of a medical triumph. $N$ Engl J Med, 370, 1576-8.

Cuadros Diego F, Branscum Adam J, Miller F. DeWolfe, AbuRaddad Laith J (2014). Spatial epidemiology of hepatitis C virus infection in Egypt: Analyses and implications. Hepatol, 60, 1150-9.

ELGendy Saad M, Mohamed Hessien, Mahmoud M. EL Sherbiny (2005). A panel of molecular markers in hepatitis c virus-related hepatocellular carcinoma. J Egyptian Nat Cancer Inst, 17, 270-8.

Feld Jordan J, Kowdley Kris V, Coakley Eoin, et al (2014).
Treatment of HCV with ABT-450/r-ombitasvir and dasabuvir with ribavirin. $N$ Engl J Med, 370, 1594-603.

Flemming Jennifer A, Ju Dong Yang, Eric Vittinghoff, W. Ray Kim, Norah A (2014). Risk prediction of hepatocellular carcinoma in patients with cirrhosis: The Adress HCC risk model. Terrault Cancer, 120, 3485-93.

Hajarizadeh Behzad, Jason Grebely, Gregory J. Dore (2013). Epidemiology and natural history of HCV infection. Nature Rev Gastroenterol Hepatol, 10, 553-62.

Hamidreza Abdolsamadi, Peiman Eini , Kieslichova E, et al. (2013). Evaluation of salivary beta-2 microglobulin as $\mathrm{HBV}$ proliferation marker in HBS Ag+, HBV DNA PCR+ and HBV DNA PCR- subjects. J Gastroenterol Hepatol, 6, 105-11.

Huang J (2002). HLA in hepatocellular carcinoma. World $J$ Gastroenterol, 8, 1007-9327.

Huckans Marilyn, Bret E. Fuller, Hannah Olavarria, et al (2014). Altered expression of peripheral immune factors is associated with neuro-psychiatric symptom severity in adults with and without chronic hepatitis $\mathrm{C}$ virus infection. Brain Behavior, 4, 123-42.

Kanwal Fasiha, Bacon Bruce R (2012). Does treatment alter the natural history of chronic HCV? Chronic Hepatitis $C$ Virus, 103-12.

Khalid SS, Hamid S, Siddiqui AA, Qureshi A, Qureshi N (2011). Gene profiling of early and advanced liver disease in chronic hepatitis C patient. $J$ Hepatol Int, 5, 782-8.

Kim JW, Wang XW (2003). Gene expression profiling of preneoplastic liver diseases and liver cancer. A new era for early detection and treatment of these deadly diseases. Carcinogenesis, 24, 363-9.

Malaguarnera M, Di Fazio I, Ferlito L (2000). Increase of serum beta 2 -microglobulin in patients affected by $\mathrm{HCV}$ correlated hepatocellular carcinoma. Eur J Gastroenterol Hepatol, 12, 937-9.

Migliaresia Sergio, Alessandro Bresciania, Luci Ambrosone, et al (2000). Increased serum concentrations of soluble HLA-class I antigens in hepatitis C virus related mixed cryoglobulinaemia. Ann Rheum Dis, 59, 20-5.

Mourad Wesam, Basuni Ashraf, Fouad Tarekb, et al (2013). The value of PIVKA-II and AFP-L3\% in the diagnosis of hepatocellular carcinoma with normal and abnormal AFP levels. Egypt Liver J, 3, 1-5.

Quiroga J, Martin J, Pardo M, Carreno V (1994). Serum levels of soluble immune factors and pathogenesis of chronic hepatitis $\mathrm{C}$, and their relation to therapeutic response to interferonalpha. Dig Dis Sci, 39, 2485-96

Riolobos Laura, Hirata Roli K, Turtle Cameron J, et al (2013). HLA engineering of human pluripotent stem cells. Molecular Therapy, 21, 1232-41.

Saito Yumi , Nobukui Oba, Syuta Nishinakagawa, et al (2010). Identification of $\beta 2$-microgloblin as a candidate for early diagnosis of imaging-invisible hepatocellular carcinoma in patient with liver cirrhosis. Oncol Reports, 23, 1325-30.

Saleh M (2012). Study the expression level of beta 2 microglobulin gene on hepatitis $\mathrm{C}$ patients before and after treatment with Interferon. Baghdad Sci J, 9, 504-10.

Tabayoyong William B. and Zavazava Nicholas (2007). Soluble HLA revisited. Leuk Res, 31, 121-5.

Ward DG, Cheng Y, N'Kontchou G, et al (2006). Preclinical and post-treatment changes in the HCC-associated serum proteome. British J Cancer, 95, 1379-83. 